\title{
Análisis y aplicación didáctica del relato de E. Pardo Bazán: "Sin pasión” (1909)
}

\author{
Pilar Couto Cantero \\ (UNIVERSIDADE DA CORUÑA) \\ pilar.couto@udc.es
}

(recibido novembro/2011, revisado decembro/2011)

RESUMEN: Este artículo está dedicado al relato de doña Emilia Pardo Bazán titulado: "Sin pasión" publicado por primera vez en 1909. De acuerdo con la línea estructural del monográfico presentado en este volumen, el relato breve objeto de estudio aborda la temática de la violencia de género. En él se propone un análisis textual planteado desde una doble perspectiva. El análisis del texto desde la semiótica literaria, prestando especial atención a los siguientes aspectos: intriga, estructura narrativa del relato y personajes. Por otra parte, se incluye un apartado específico en el que se exploran las posibilidades didácticas de este texto desde el punto de vista de la didáctica de la lengua y la literatura (DLL).

PALABRAS CLAVE: análisis textual, didáctica, violencia de género, DLL.

ABSTRACT: This article is devoted to the short-story: "Sin pasión" written by Emilia Pardo Bazán in 1909. This short-story deals with domestic violence against women. A textual analysis will be presented both from the literary semiotics perspective, with special attention focused on: topic, structure, characters, time and space, and from the teaching and learning languages perspective.

KEY WORDS: Didactology, Literary Semiotics, Violence against Women.

\section{MARCO INTRODUCTORIO}

El relato elegido para la elaboración de este artículo es un cuento escrito por Emilia Pardo Bazán titulado: "Sin pasión" que fue publicado por primera vez en 1909. El texto en el que nos hemos basado para realizar el análisis y todas las citas que de él refiramos en adelante se incluyen en la edición digital a partir de Blanco y Negro, $n^{\circ}$ 930, 1909 y cotejada con la edición de Juan Paredes Núñez Cuentos completos, La Coruña, Fundación Pedro Barrié de la Maza, Conde de Fenosa, 1990, t. III, pp. 89-91. Pero antes de comenzar el análisis en sí mismo hemos creído conveniente realizar un breve recorrido a través de ciertos aspectos biográficos de doña Emilia Pardo Bazán que creemos muy pertinentes y están intrínsicamente ligados a su trayectoria literaria.

Partiendo del contexto social e histórico en que vivió y, habida cuenta que era una mujer con una posición privilegiada, uno podría preguntarse por qué la Condesa siempre manifestó sus inquietudes y preocupaciones relacionadas con el tema central de este cuento que no es otro que el maltrato a las mujeres y la desigualdad social entre ambos sexos. Quizás alguno de los argumentos que siguen a continuación 
arroje luz a esta cuestión. En primer lugar, conviene resaltar que A Coruña, lugar de nacimiento de la escritora, era considerada una de las ciudades más liberales de la España de la época, lo cual podría constituir un factor que facilitase el desarrollo de este tipo de pensamientos.

En segundo lugar, es importante saber que Emilia Pardo Bazán, nacida en el año 1851, era hija única de un matrimonio con antecedentes nobiliarios y tuvo la suerte de tener un padre progresista, partidario de la educación de las mujeres y de la igualdad de derechos entre éstas y los hombres. Fue precisamente don José Pardo Bazán ${ }^{\mathbf{I}}$ quien confesó un día a su hija que los hombres son seres egoístas por naturaleza y que no había nada que hiciesen los hombres que no pudiesen hacer las mujeres, debido a la imposibilidad de la existencia de dos morales distintas para dos sexos.

La vida y obra de la escritora de Marineda quedaría marcada desde entonces por estas palabras hasta el final de sus días y es quizás, por todo ello, que la denuncia contra la desigualdad existente entre los hombres y mujeres de su época tanto desde el punto de vista social, cultural, como económico, se verá reiteradamente reflejada en la obra pardobazaniana. En gran parte de su legado, unas veces presente y otras de un modo subyacente, se aprecia esta temática abordada por su autora desde diferentes perspectivas: el maltrato psicológico, la tiranía doméstica, la venganza hacia el maltratador, el maltrato físico a la mujer o varias juntas en el mismo texto llegando, incluso, al asesinato y suicidio de algunos de sus personajes.

Todos estos antecedentes nos han llevado a plantear la siguiente hipótesis: Emilia Pardo Bazán era conocedora y estaba muy al tanto del terrible asesinato de su abuela paterna descrito y documentado fehacientemente en el primer artículo que da comienzo a este monográfico y que, por lo tanto, necesitaba exteriorizar de alguna manera ese grave suceso que, tal y como se ha demostrado, fue eliminado del archivo familiar y ocultado por la familia durante generaciones. El hecho de utilizar este tema como inspiración y eje vertebral que conforma la intriga de varios de sus textos de ficción bien podría constituir una especie de catarsis con la que redimir en su nombre y el de su familia tal atrocidad y aliviar el sentimiento de culpabilidad. No en vano desde hace décadas la escritura de textos de ficción se está utilizando con fines terapéuticos para canalizar la liberación de las mentes de conflictos irresolutos o que, de algún modo, preocupan a sus autores.

Pero tal fue el grado de compromiso por la denuncia del maltrato y la desigualdad hacia la mujer, que Emilia Pardo Bazán no sólo inicia su denuncia social a través de sus escritos literarios y periodísticos, sino que irá aún más lejos solicitando formalmente y en varias ocasiones la reforma del Código Civil de 1889 que no definía

\footnotetext{
${ }^{\text {I }}$ En el prólogo a la traducción en español de la obra de J. S. Mill: La esclavitud femenina, a finales del S. XIX, ella misma escribe aludiendo a su padre: "Guiado por ese instinto, juzgaba y entendía de un modo tan diferente de como juzga la mayoría de los hombres, que con haber tratado yo después a bastantes de los que aquí pasan por superiores, en esta cuestión de los derechos de la mujer rara vez les he encontrado a la altura de mi padre".
} 
claramente en qué términos el marido debía de proteger a su esposa y sí especificaba, sin embargo, la imposición de obediencia por parte de la mujer a su cónyuge. Así lo afirma Herrero Figueroa en otro artículo de este mismo volumen advirtiendo que:

Doña Emilia (...), hablará de las leyes discriminatorias para con la casada, al tiempo que solicita la reforma del Código Civil de 1889 que imponía a la mujer obediencia a su marido y en cuanto a este se limitaba a obligar a la protección de su esposa, pero sin definir ni precisar de qué género de protección se trataba, imprecisión esta que, como otras insuficiencias denuncia, si bien reconociendo que las costumbres eran aun más retrógradas que las leyes. Y por ello, sobre la base de la legislación española, insistirá en que se debería modificar el derecho en el sentido de defender a la mujer y potenciar la equidad porque la sociedad y no la naturaleza es la que la rebaja y somete. (Herrero Figueroa 2011-2011: 68-69)

Teniendo en cuenta los datos que hemos apuntado sobre la vida de Emilia Pardo Bazán y habida cuenta que fue la primera mujer española que ocupó una cátedra en la Universidad, la primera periodista y corresponsal profesional de la Península, la principal ideóloga del feminismo decimonónico en España y la gran narradora en castellano del siglo XIX, parece oportuno concluir que nadie mejor que esta mujer podía estar capacitada para denunciar estas diferencias sociales a través de sus escritos.

Desde su primera publicación en 1876 basada en un estudio sobre el Padre Feijóo se advierte su inquietud por la defensa de la igualdad entre mujeres y hombres, pues este monje gallego del siglo XVIII defendió en sus trabajos los derechos de las mujeres. Sus preferencias ideológicas y novelísticas siempre estuvieron centradas en escritores o filósofos declarados feministas como el arriba citado John Stuart Mill a quien admiraba profundamente y alguna de cuyas obras prologó. Tal y como ella misma indica en el prólogo de la traducción al castellano de: The Subjection of Women (1869) traducido como: La esclavitud femenina (s.a.) "el cambio en la condición de la mujer, hasta el límite que la equidad y la razón prescriben, es ante todo y sobre todo un progreso moral, dificilísimo de plantear en el día, según reconoce y pone de manifiesto Stuart Mill en distintos pasajes de su libro"3.

Tal y como hemos afirmado, Emilia Pardo Bazán reivindicó los derechos de las mujeres pero nunca asumió una posición de víctima, ni siquiera cuando la Real Academia Española rechazó una y otra vez la posibilidad de que ella ocupara uno de los treinta y seis sillones con la única excusa de que era una mujer. Tampoco quiso ocultarse bajo un seudónimo masculino a pesar de que hubo quienes llegaron a pensar que su obra fue escrita por un hombre con seudónimo de mujer.

Lo cierto es que sólo una mentalidad progresista como la suya pudo haber escrito a principios del siglo XX que: "el movimiento feminista es la única conquista

\footnotetext{
${ }^{2}$ Con sólo veinticinco años derrotó en un certamen de ensayo a Concepción Arenal con una obra sobre el Teatro del Padre Feijóo.

3 En este libro John Stuart Mill habla sobre el rol femenino en el matrimonio y la grave necesidad de cambio que requiere. El prólogo de la edición traducida de finales de siglo XIX (189-) es de Emilia Pardo Bazán.
} 
totalmente pacífica que Ileva trazas de obtener la humanidad. El mejoramiento de la condición de la mujer ofrece estas dos notas que conviene no perder nunca de vista: a) que no cuesta ni puede costar una gota de sangre; b) que coincide estrictamente su incremento con la prosperidad y grandeza de las naciones donde se desenvuelve. Ejemplo: el Japón, Rusia, Inglaterra, Suecia, Noruega, Dinamarca, Estados Unidos"4.

En 1868 la condesa se casó con un estudiante de abogacía, José Quiroga, con el que tuvo, después de ocho años, su primer hijo, al que dedicó su único libro de poesía titulado, significativamente, Jaime. Luego nacerían sus hijas Blanca y Carmen pero el nacimiento de éstas no empañaría su deseo de continuar escribiendo sino todo lo contrario, en la década de los ochenta llegó a entregar prácticamente una novela por año, además de multitud de artículos y cuentos.

A pesar de que en sus libros retratase maridos iracundos y entre los múltiples personajes de sus más de quinientos relatos suelen aparecer hombres rústicos que despliegan su violencia contra esposas, hijas, sobrinas y sirvientas; en este caso, no parece haber sido ésta su experiencia vivida con José Quiroga. Por el contrario, convendría destacar también que, a menudo, las ideas feministas de Pardo Bazán fueron promulgadas por personajes de ficción masculinos, tal es el caso del comandante Gabriel Pardo que aparece y reaparece en varias de sus novelas o del propio Juan Vela en el relato que vamos a analizar: "Yo en jamás le levanté la mano ni a mi madre ni a mis hermanas...", "Es mala vergüenza para un hombre el sacudir a las hembras, y más si son como la Remigia, que se cae de puro honrá".

Su profunda admiración por el pueblo y su mirada aguda sobre la cultura de los campesinos $^{5}$, la ayudaron a afianzar su convicción en la igualdad de los sexos y en el derecho de las mujeres a la educación y al trabajo. Así lo escribía en uno de sus artículos publicado en La España Moderna:

En gran porción del territorio español, la mujer ayuda al hombre en las faenas del campo, porque la igualdad de los sexos, negada en el derecho escrito y en las esferas donde se vive sin trabajar, es un hecho ante la miseria del labrador, del jornalero o del colono. En mi país, Galicia, se ve a la mujer, encinta o criando, cavar la tierra, segar el maíz y el trigo, pisar el tojo, cortar la hierba para los bueyes. [...] El pobre hogar de la mísera aldeana, escaso de pan y fuego, abierto a la intemperie y al agua y al frío, casi siempre está solo. A su dueña la emancipó una emancipadora eterna, sorda e inclemente: la necesidad ${ }^{6}$.

Emilia Pardo Bazán hizo todo a pesar de ser mujer, sin dejar de ser mujer y reivindicando su condición de ser mujer, hecho que constituye aún hoy en día un ejemplo para muchos ciudadanos de lo que significa la igualdad de sexos en libertad.

\footnotetext{
4 Pardo Bazán, Emilia (25-I-1904): “La Vida Contemporánea”, en La Ilustración Artística. (Dorado 2005: 252).

5 Su padre José Pardo Bazán ya había mostrado su preocupación por el problema de la propiedad rural en Galicia en las páginas de la Revista de Galicia (1850). Pardo-Bazán, José: "Estudios sobre la propiedad en Galicia. Foros: su historia, ventajas e inconvenientes", Revista de Galicia, 1-VI-1850.

6 Pardo Bazán, Emilia (agosto de 1890):154.
} 
Fue la primera gran periodista española, escribiendo sin cesar hasta su muerte; fue la primera corresponsal en el extranjero (Roma y París); fundó y dirigió el Nuevo Teatro Crítico; recogió en "La cuestión palpitante" su textos sobre estética naturalista en el diario La Época; y reunió sus artículos feministas en "La Mujer Española", acaso el libro más importante y menos conocido del feminismo español. Con La Tribuna (1883) logra su primera obra completa dentro de la estética naturalista a la que dedicó el ensayo ya citado: La cuestión palpitante, prologado por Clarín y muy criticado por casi todos los escritores de la época excepto Galdós. El personaje de la cigarrera y revolucionaria Amparo fue caracterizado como el de una mujer moderna pero a la vez delicada, un personaje complejo pero arrollador y con estilo.

Tras retratar lo urbano, Doña Emilia, empleó su pluma en retratar un campo gallego violento, sensual, Ileno de contrastes sociales y culturales. Como ya se ha dicho, cultivó el Ilamado Naturalismo, que hoy en día nos parece una literatura normal, sin censura y con predilección por conflictos sociales. Prueba de ello son las dos obras de todos conocidas: Los pazos de Ulloa (1886) y La madre naturaleza (1887). Seis libros de cuentos, la publicación de La sirena negra en 1908 y Dulce Dueño en 1911 fueron sus últimas aportaciones antes de morir el 12 de mayo de 1921, no sin antes haber conseguido el citado cargo de Catedrática de Literatura contemporánea de las lenguas neolatinas. Su legado periodístico y gran aportación literaria fueron objeto de crítica y estudio durante el siglo pasado, pero sus escritos siguen estando vigentes en la actualidad hecho que queda sobradamente probado a la luz de ésta y otras muchas publicaciones que giran a su alrededor.

\section{PRESENCIA DEL MALTRATO HACIA LA MUJER EN OTROS RELATOS DE EMILIA PARDO BAZÁN}

Como ya apuntábamos en el apartado anterior son muchos los relatos y novelas pardobazanianos que tratan la temática del maltrato a la mujer tanto desde el punto de vista psicológico como físico. El primer cuento que podría considerarse netamente feminista en la literatura española del siglo XIX se titula: "El encaje roto" (1897) y está incluido en un volumen titulado, curiosamente, Cuentos de Amor. En él se refleja el temor de una mujer ante una futura vida conyugal llena de posibles conflictos. Minutos antes de casarse, esta mujer que está probándose el velo de novia lo rasga sin querer. Este pequeño contratiempo le permite divisar la cara de furia del marido ante su presunta torpeza y el odio reflejado en su rostro constituye un indicio claro para ella permitiéndole, contra todo pronóstico, renunciar al casamiento a pesar de todo:

Al precipitarme para saludarle llena de alegría por última vez, antes de pertenecerle en alma y cuerpo, el encaje se enganchó en un hierro de la puerta, con tan mala suerte, que al quererme soltar oí el ruido peculiar del desgarrón y pude ver que un jirón del magnífico adorno colgaba sobre la falda. Solo que también vi otra cosa: la cara de Bernardo, contraída y desfigurada por el enojo más vivo; 
sus pupilas chispeantes, su boca entreabierta ya para proferir la reconvención y la injuria... No llegó a tanto porque se encontró rodeado de gente; pero en aquel instante fugaz se alzó un telón y detrás apareció desnuda un alma. (Pardo Bazán, Emilia: 1897$)^{7}$.

El personaje de Nicolás Abreu que, "como todos los que a los cuarenta años se vuelven severos moralistas, tuvo una juventud divertida y agitada... acordó casarse, como el que acuerda mudarse a un piso más sano", refleja el machismo dominante tal y como se desprende de la lectura del relato titulado: "Feminista" (1909). Claramente el narrador de este cuento expresa que "ellas nacieron para cumplir deberes, amamantar a sus hijos y espumar el puchero". Es por ello que, Nicolás en el mismo día de su luna de miel obliga a su ya esposa Clotilde a ponerse sus pantalones como símbolo de autoridad indiscutible:

He querido que te pongas los pantalones en este momento señalado para que sepas, querida Clotilde, que en toda tu vida volverás a ponértelos. Que los he de Ilevar yo, Dios mediante, a cada hora y cada día, todo el tiempo que dure nuestra unión, y ojalá sea muchos años, en santa paz, amén. Ya lo sabes. Puedes quitártelos. (Pardo Bazán, Emilia: 1909) ${ }^{8}$.

La recopilación de relatos titulada: Cuentos de Navidad y Reyes recoge otra interesante aportación con un relato titulado: "De Navidad" (1896). El padre de la bondadosa Lucía es un conocido tirano que gobierna en una ciudad italiana del siglo XVI Ilamada Montenero. Conocido por su barbarie Orso Amadei se dispone a abusar sexualmente de una joven en una de sus habituales orgías. La descripción del suceso como si de una cacería se tratase habla por si mismo:

Si se mezclaba con ellos alguna mujer, era la infeliz juglaresa sorprendida en la plaza pública, y que, después de servir de ludibrio a los convidados, aparecía al día siguiente con el cuerpo acardenalado, medio muerta, arrojada en cualquier callejuela de la ciudad. Aquella noche, Ridolfi, uno de los capitanes de Orso, había anunciado mejor presa: justamente acababa de cazar a una joven muy linda, ipeor para ella si andaba a tales horas por la calle! Alborotáronse los bebedores; Orso, riendo a carcajadas, ordenó que trajesen a la jovencita, que entró, empujada por los soldados, temblorosa, desgreñado el rubio pelo, y los hombres se engrieron al verla, porque era en verdad soberanamente hermosa.

Orso clavó en ella sus ojos impúdicos; tendió la mano, apartó los rizos de oro... (Pardo Bazán, Emilia: 1896)9.

\footnotetext{
7 Pardo Bazán, Emilia (1897): El Liberal, 19 septiembre 1897. Edición digital a partir de la de OO. CC. (Madrid, Aguilar, 1963, 4a ed., T. I, pp. 1120-1211) y cotejada con la edición de Juan Paredes Núñez (Cuentos completos, La Coruña, Fundación Pedro Barrié de la Maza, Conde de Fenosa, 1990, T. I, pp. 245-357).

8 Pardo Bazán, Emilia (1909): Sud-exprés (Otros cuentos), O.C. T. XXXVI, 1909, pp. 256-260.

9 Pardo Bazán, Emilia (1896): La Época, 1896. Edición digital a partir de la de OO. CC. (Madrid, Aguilar, 1963, 4ª ed., T. I, pp. 1469-1512) y cotejada con la edición de Juan Paredes Núñez (Cuentos completos, La Coruña, Fundación Pedro Barrié de la Maza, Conde de Fenosa, 1990, T. II, pp. 205-259).
} 
En el relato titulado "La novia fiel" (1894) recogido también en el libro irónicamente titulado Cuentos de amor, será Amelia la que sin recibir ningún tipo de maltrato físico se irá consumiendo y enfermando poco a poco, tardando casi nueve años en ver la luz y darse cuenta de que su novio no tenía prisa en casarse porque tal y como le decían sus amigas: “ßien inocente serías si creyeses que no te la pega!...”.

Un día.... sin saber cómo, sin que ningún suceso extraordinario, ninguna conversación sorprendida la ilustrase, acabaron de rasgarse los últimos cendales del velo... Amelia veía la luz; en su alma relampagueaba la terrible noción de la realidad; y al acordarse de que poco antes admiraba la resignación de Germán y envidiaba su paciencia, y al explicarse ahora la verdadera causa de esa paciencia y esa resignación incomparables.... una carcajada sardónica dilató sus labios, mientras en su garganta creía sentir un nudo corredizo que se apretaba poco a poco y la estrangulaba. La convulsión fue horrible, larga, tenaz; y apenas Amelia, destrozada, pudo reaccionar, reponerse, hablar.... rogó a sus consternados padres que advirtiesen a Germán que las relaciones quedaban rotas. Cartas del novio, súplicas, paternales consejos, todo fue en vano. Amelia se aferró a su resolución, y en ella persistió, sin dar razones ni excusas. (Pardo Bazán, Emilia: 1894) ${ }^{\mathrm{IO}}$.

En "La advertencia" (s. a.) recogido en Cuentos de la tierra, el médico del pueblo recomienda a la joven Maripepa de Norla para ir a Madrid a ejercer de ama de cría amamantando al hijo recién nacido de los amos. El pago por ello es sustancial y, dada su situación económica y al no poder negarse, el marido de la protagonista se tiene que conformar con establecer los límites de su territorio no sin advertirle del siguiente modo, aunque más que una "advertencia" como reza el título parece una amenaza:

Y, de pronto, agarrando por el pescuezo a Maripepa, la besó sin arte, restregándole la cara.

-Cata que eres moza y de buen parecer -refunfuñaba entre estrujones-. Cata que no se vayan a divertir a mi cuenta los señoritos... Tú vas para el chiquillo y no para los grandes, ¿óyesme? En Madrid hay una mano de pillería. Como yo sepa lo menos de tu conducta, la aguijada de los bueyes he de quebrarte en los lomos... (Pardo Bazán, Emilia: s. a.) ${ }^{\mathbf{I I}}$.

En "Las medias rojas" (1914), el narrador recoge la brutal paliza que un padre propina a su hija sólo porque se ha comprado unas medias. Ildara, que así se Ilama la víctima, aprieta los dientes por no gritar de dolor e intenta defender su cara con las manos. Siempre estaba asustada pensando que su propio padre podía hacerle daño, como ya le había sucedido a su prima, a quien su madre había dejado marcada la frente con el aro de la criba. El siguiente párrafo ratifica los temores de Ildara y supera, en nuestra opinión, los límites de la ficción:

\footnotetext{
Io Pardo Bazán, Emilia (11-II-1894): El Liberal.

I I Pardo Bazán, Emilia (s. a.): “La advertencia” recogido en Cuentos de la tierra.
} 
Y con el cerrado puño hirió primero la cabeza, luego, el rostro, apartando las medrosas manecitas, de forma no alterada aún por el trabajo, con que se escudaba Ildara, trémula. El cachete más violento cayó sobre un ojo, y la rapaza vio como un cielo estrellado, miles de puntos brillantes envueltos en una radiación de intensos coloridos sobre un negro terciopeloso. Luego, el labrador aporreó la nariz, los carrillos. Fue un instante de furor, en que sin escrúpulo la hubiese matado, antes que verla marchar, dejándole a él solo, viudo, casi imposibilitado de cultivar la tierra que llevaba en arriendo, que fecundó con sudores tantos años, a la cual profesaba un cariño maquinal, absurdo. Cesó al fin de pegar; Ildara, aturdida de espanto, ya no chillaba siquiera. (Pardo Bazán, Emilia: 1914) ${ }^{\mathbf{I 2}}$.

En el relato que lleva por título: "En tranvía" (1890) recogido en un volumen titulado con más tino a nuestro juicio: Cuentos dramáticos, el lector es conocedor del drama terrible de una mujer con pocos recursos que, totalmente desesperada y fuera de sí, se acurruca en una esquina de un tranvía junto a su hijo. Aparte de la miseria y estado de desamparo en que se encuentra la mujer, lo que queremos precisar a continuación al hilo del tema objeto de nuestro estudio, es el maltrato recibido por parte de su marido que no contento con propinarle varios palos en la cabeza se marcha con otra dejando a la primera en la indigencia:

-Se me ha ido con otra -repitió entre el silencio y la curiosidad general-. Una ladronaza pintá y rebocá, como una paré. Con ella se ha ido. Y a ella le da cuanto gana, y a mí me hartó de palos. En la cabeza me dio un palo. La tengo rota. Lo peor, que se ha ido. No sé dónde está. ¡Ya van dos meses que no sé! (Pardo Bazán, Emilia: 1890$)^{\mathbf{I} 3}$.

En Cuentos de Marineda se halla recogida otra interesante aportación: "El indulto". Se trata de un cuento publicado en 1883 en el que el tema está presente centrándose en el maltrato psicológico a la mujer con un asesinato incluido. Un marido, al que nunca se cita con nombre y apellidos sino con sustantivos como: "criminal", "asesino" y "carnicero" ha ido a la cárcel por asesinar a su suegra. Debido a ciertas engañifas y arteras tretas legales el sujeto consigue ser indultado y la protagonista, Antonia, al ser conocedora de este suceso vive en un estado permanente de pánico tras ser amenazada de muerte. El narrador lo pone de manifiesto en los siguientes términos:

Y el destino de Antonia comenzó a infundir sagrado terror cuando fue esparciéndose el rumor de que su marido "se la había jurado» para el día en que saliese del presidio, por acusarle. La desdichada quedaba encinta, y el asesino la dejó avisada de que, a su vuelta, se contase entre los difuntos.

\footnotetext{
I2 Pardo Bazán, Emilia (1914): Por esos mundos. Edición digital a partir de la de OO. CC. (Madrid, Aguilar, 1964, T. II, pp. 1474-1566) y cotejada con la edición de Juan Paredes Núñez (Cuentos completos, La Coruña, Fundación Pedro Barrié de Maza, Conde de Fenosa, 1990, T. III, pp. 193-308).

I3 Pardo Bazán, Emilia (1890): El Imparcial, 24 febrero.
} 
....se oían exclamaciones de horror. ¡La ley, en vez de protegerla, obligaba a la hija de la víctima a vivir bajo el mismo techo, maritalmente con el asesino!... (Pardo Bazán, Emilia: 1883) ${ }^{\text {I4 }}$.

Un grupo de aldeanos han dado captura a un supuesto "Rabeno" (1910) en el relato con el mismo nombre analizado en este mismo volumen por Carballal Miñán (2010-2011: 97-106) tras haber intentado agredir a una de las jóvenes de la aldea, la hija del tabernero. Ante la impotencia del médico, que intenta desesperadamente buscar una solución racional a este suceso, los vecinos del pueblo propinan una paliza terrible al desconocido al que finalmente, casi muerto, arrojan al mar:

Y los golpes, los denuestos, las injurias, los roncos aullidos de los mozos, que venían siguiendo al Rabeno desde otra parroquia, yéndole a los alcances, como alanos tras de la res, arreciaban; y en vano el doctor, suplicando, mandando, quería intervenir, interponerse para salvar al que acaso no era ya sino un cadáver... ¡En aquel mismo momento, con redoble fiereza, lo lanzaban, desgarrado en los escollos, al mar, tan azul, tan tranquilo! (Pardo Bazán, Emilia: 1910) ${ }^{\mathbf{1 5}}$.

Pero es al utilizar animales como protagonistas de sus cuentos cuando Emilia Pardo Bazán realiza sus críticas más severas contra la violencia doméstica. Un ejemplo de ello es el relato recogido en el volumen: Cuentos nuevos que lleva por título: "Piña" (1890). Con este relato, la autora reflexiona sobre la hipocresía de la sociedad a la que, de algún modo, considera culpable por no denunciar casos de violencia doméstica de todos conocidos a la vez que incapaz de ayudar a las víctimas. Bajo el disfraz de una pareja de monos: Coco y Piña, la escritora reflexiona duramente sobre la violencia de género:

Miedo, ¿por qué? He aquí el problema que preocupaba, cuando me ponía a reflexionar en la suerte de la maltratada cubanita. Su marido, por mejor decir, su tirano, era de la misma estatura que ella; ni tenía más fuerza, ni más agilidad, ni más viveza, ni dientes más agudos, ni nada, en fin, sobre qué fundar su despotismo. ¿En qué consistía el intríngulis? ¿Qué influjo moral, qué soberanía posee el sexo masculino sobre el femenino, que así lo subyuga y lo reduce, sin oposición ni resistencia, al papel de pasividad obediente y resignada, a la aceptación del martirio? (Pardo Bazán, Emilia:1890) ${ }^{\mathbf{I}}$.

El narrador colectivo en este relato, que no es otro que la sociedad en general, está intencionadamente en primera persona del plural, esa pluralidad le sirve a la

\footnotetext{
I4 Pardo Bazán, Emilia (1883): La Revista Ibérica, núm. 1. Edición digital a partir de Obras Completas. Vol. I, 4ª ed., Madrid, Aguilar, 1964, pp. 1063-1119.

I5 Pardo Bazán, Emilia (1910): La Ilustración Española y Americana, núm. 10. Edición digital a partir de la de La Ilustración Española y Americana, núm. 10, 1910 y cotejada con la edición de Juan Paredes Núñez, Cuentos completos, La Coruña, Fundación Pedro Barrié de la Maza, Conde de Fenosa, 1990, T. IV, pp. 151-154.

I6 Pardo Bazán, Emilia (1890): La Ilustración Artística, núm. 447, 1890. Edición digital a partir de Obras Completas. Vol. II, 4ª ed., Madrid, Aguilar, 1964, pp. 1387-1473.
} 
autora para denunciar cómo esa sociedad se oculta entre la multitud y mira para otro lado ante supuestos casos de maltrato doméstico. En "Piña", al contrario que en otros cuentos, esa sociedad tan criticada por la condesa decide actuar para evitar un terrible final aunque no dejará de ser igualmente el mismo, puesto que la mona al ser libre muere no siendo capaz de adaptarse al nuevo y frío entorno en el que vive:

Nosotros habíamos desempeñado hasta entonces el papel de la sociedad, que no gusta de mezclarse en cuestiones domésticas y deja que el marido acabe con su mujer, si quiere, ya que al fin es cosa suya; pero ante el exceso del mal, determinamos convertirnos en Providencia, y estableciendo en la jaula una división, encerramos en ella al verdugo, dejando sola y libre a la mártir. (Pardo Bazán, Emilia:1890) ${ }^{17}$.

Mención aparte merecería el estudio del maltrato a la mujer y la desigualdad social desde el punto de vista de los narradores y de los personajes incluidos en la obra novelística de Emilia Pardo Bazán. Entendemos que harían demasiado extenso el volumen de este artículo y por ello hemos optado por dejarlos fuera de esta investigación no sin antes dejar un breve apunte sobre algunos de sus personajes. En La Piedra Angular, la hija menor del zapatero Antiojos muere a causa de la paliza que éste le propina; el personaje de Sabel en Los pazos de Ulloa recibe un montón de golpes del marqués y el ataque que sufre la protagonista del mismo nombre en Doña Milagros por parte de su asistente constituyen algunos ejemplos de momentos de máxima tensión que bien podrían ser explorados desde distintos puntos de vista en otro estudio.

\section{ANÁLISIS Y APLICACIÓN DIDÁCTICA DEL RELATO: "SIN PASIÓN"}

El relato seleccionado para realizar el análisis que sigue se titula: "Sin pasión" y fue publicado por primera vez en el año 1909. Cualquiera de los otros relatos mencionados en este artículo e incluso otros que no han sido citados por cuestiones de espacio serviría para la realización de un análisis de características similares al que a continuación proponemos.

\subsection{Análisis semiótico-textual}

Tal y como lo define el diccionario de la RAE, el término "diégesis" se entiende como el desarrollo narrativo de los hechos en una obra literaria. Procedemos pues a introducir este análisis con un breve resumen de la diégesis para poner al lector en antecedentes. Juan, apodado "el Costilla", es el inquilino del matrimonio Rivas quien, un día, cansado de presenciar en repetidas ocasiones los abusos proferidos por parte del "Negruzco" hacia su esposa lo mata a golpes:

... el Negruzco entró en su casa de mal talante, y sin reparar que estaba yo allí, y también el mayor de los niños, una criatura de ocho años, la tomó con la

\footnotetext{
I7 (Vid. Nota 16).
} 
Remigia, y por primera providencia le pegó puñetazos en el pecho. Y como ella se echó a llorar, le dio una patá en una pierna que la tiró al suelo, y ya que la vio en el suelo, alzó una silla para darle Dios sabe dónde... Y entonces, un servidor..., no..., el demonio... Me lo hubiese comido, vamos; le di tantas, sin saber lo que estaba haciendo, que me contaron después que hasta le "seccioné" una oreja y tres dedos de la mano... No, por avisado no fue; que se lo advertí veces. ¡Y no hubo más;... ¡Ahi $\mathrm{Si}$. El chico pequeño, cuando yo me harté de dar, vino a mirar a su padre, que ya no se movía, y me dijo muy calladito: “ßBien hecho!” (Pardo Bazán, Emilia:1909) ${ }^{\mathrm{I}}$.

Se trata, pues, de un texto de ficción en el que el ambicioso abogado Jacinto Fuentes se plantea la defensa del presunto homicida Juan Vela, oficial de zapatero de oficio, acusado de asesinato por defender a "la Remigia" de su propio esposo Eugenio Rivas, conocido como "el Negruzco". En este relato, tan breve, pero a la vez tan intenso, se pueden diferenciar claramente dos tramas. Por una parte, los deseos de triunfar de un joven y ambicioso "abogadito, de recortada y perfumada barba" que intenta por todos los medios que su defendido le proporcione los argumentos que necesita para dirigir su "brillante peroración forense" y, de este modo, poder alcanzar sus fines lucrativos, fama y gloria. Para ello será capaz, incluso, de pedir al reo que mienta forzando un crimen pasional que, en realidad, nunca existió:

- ¿Por qué no dice usted, cuando llegue el caso, que andaba usted prendado de la Remigia?

Porque sólo con verla, señor, no lo creerán... Y tampoco es mu regular eso de caluniar a una mujer decente (vid. nota 18).

Por otra parte, a través del interrogatorio del abogado a su defendido en la cárcel Modelo, Juan Vela, el "Costilla" ${ }^{19}$ y verdadero protagonista de este relato, cuenta lo ocurrido en el día de la "desgracia". Vela presencia en varias ocasiones episodios de malos tratos por parte de Eugenio Rivas a su esposa; comprueba, además, que no hay ningún motivo para ello porque "la Remigia" era muy buena y advierte, también en varias ocasiones, al "Negruzco" para que no lo haga, por lo menos, en público. Pero éste se ensaña con su mujer, le pega puñetazos, la tira al suelo y cuando coge una silla para seguir propinándole..., Vela interviene como poseído por el demonio y mata al agresor.

Pero a mí, me llevaba el demonio viendo el trato que le daba aquel tío a su mujer delante de mí. Que la matase allá en su alcoba, malo será; pero nadie tié que meterse; para eso era su señora. En mi cara..., era cosa de avergonzarme. Estar un hombre presenciando que a una mujer la hacen tajás, y dejarlo... vamos,

\footnotetext{
I 8 Pardo Bazán, Emilia (1909): “Sin pasión” edición digital a partir de Blanco y Negro núm. 930, 1909 y cotejada con la edición de Juan Paredes Núñez Cuentos completos, La Coruña, Fundación Pedro Barrié de la Maza, Conde de Fenosa, 1990, t. III, pp. 89-91.

${ }^{\text {I9 }}$ Nótese que el nombre, el apellido y el apodo del supuesto homicida evocan cuando menos: fragilidad, inconsistencia, vulgaridad...
} 
que se le requema a uno la sangre. Yo en jamás le levanté la mano ni a mi madre ni a mis hermanas cuando vivía con ellas. Es mala vergüenza para un hombre el sacudir a las hembras, y más si son como la Remigia, que se cae de puro honrá" (vid. nota 18).

Se considera estructura a la red de relaciones de dependencia mutua que se establece entre todos los elementos que componen un conjunto $\mathrm{y}$, por lo tanto, la estructura narrativa de un relato resulta de la transformación de una historia en un discurso mediante elementos como la modalización, la temporalización y la espacialización. Centrémonos pues en el primero de estos elementos que corresponde a la entidad responsable de contar la historia en primer lugar y al análisis de su estructura narrativa en segundo lugar. Se trata de un narrador omnisciente en tercera persona, o si prefiere utilizando la terminología genettiana, un narrador heterodiegético, porque es otra entidad la que cuenta la historia que, a su vez es extradiegético, porque está fuera de la misma no formando parte de los personajes. Un narrador, en cualquier caso, conocedor de todos y cada uno de los detalles de la historia e incluso de los pensamientos de los protagonistas tal y como observamos al final del cuento al leer: "pensó el defensor malhumorado, y resolviendo ya, en su interior, no apretar...". El lector comprende con estas palabras que el narrador no sólo conoce los pensamientos del personaje sino que también sabe que está malhumorado porque los acontecimientos no se desarrollan como a él le gustaría e incluso va más allá Ilegando a predecir lo que será la sentencia final contra el reo al finalizar el relato.

En cuanto a la estructura narrativa podemos afirmar que es cerrada y es circular porque comienza y termina con la figura del narrador. En un primer nivel narrativo extradiegético (NN1) se divide en tres partes que corresponden a una introducción (1), el desarrollo de los acontecimientos en sí mismo o nudo (2) y el desenlace o final (3). Esta misma fórmula modal se produce en las tres partes citadas atendiendo al mismo esquema que consiste en una pequeña narración $(\mathrm{N})$ seguida de un diálogo (D) entre el abogado (A) y el reo (R). En la parte central que se refiere al desarrollo de la historia (2) la estructura dialogal se multiplica por tres reforzando la trama e incluyendo un segundo nivel narrativo de la mano del acusado en el que se sitúa su punto climático (PC).

Como avanzábamos arriba, dentro de esta aparentemente simple estructura tripartita se incluye un segundo nivel narrativo intradiegético (NN2) que corresponde al relato del acusado en primera persona acerca del día de la "desgracia" tal y como se ejemplifica a continuación: "Yo tomé posada...", "a mí me llevaba el demonio...", "yo en jamás le levanté...", "yo le replicaba...", etc. Este tipo de estructuras metanarrativas en las que se insertan relatos dentro de otros relatos responden a una técnica narrativa que se conoce con la expresión francesa, perteneciente al lenguaje de la heráldica, mise en abyme. Si convertimos la información facilitada en los párrafos anteriores en una fórmula derivada del análisis estructural del relato ésta quedaría como sigue a continuación: 
NN $1[1 \mathrm{~N}-\mathrm{D}(\mathrm{A}+\mathrm{R})][2 \mathrm{~N}-\mathrm{D}(\mathrm{A}+\mathrm{R})(\mathrm{A}+\mathrm{R})(\mathrm{A}+\mathrm{R} \mathbf{N N} 2)][3 \mathrm{~N}-\mathrm{D}(\mathrm{A}+\mathrm{R})-\mathrm{N}]$

O de otro modo:

\begin{tabular}{|ll} 
& $1[N-D(A+R)]$ \\
$N N 1$ & $2[N-D(A+R)(A+R)(A+R$ NN 2$)]$ \\
& $3[N-D(A+R)-N]$
\end{tabular}

Para completar esta fórmula relativa a la estructura narrativa de un modo más visual y atrayente hemos propuesto el siguiente cuadro explicativo:

\section{Estructura narrativa}

Nivel Narrativo 1 (NN 1)

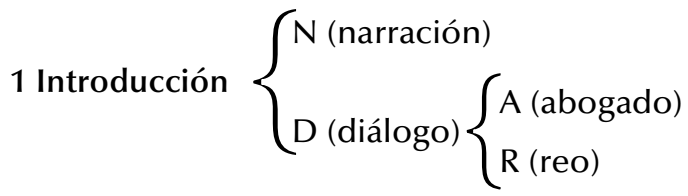

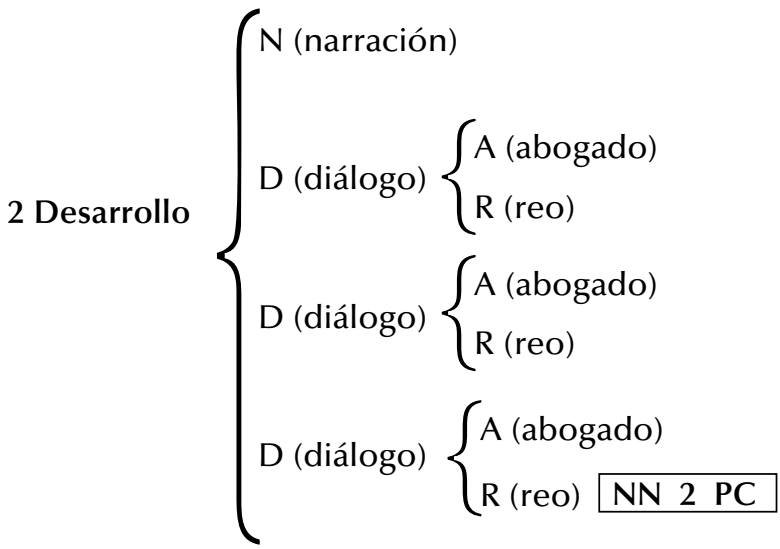

Nivel Narrativo 2 Punto Climático

3 Desenlace $\left\{\begin{array}{l}N \text { (narración) } \\ D \text { (diálogo })\left\{\begin{array}{l}A \text { (abogado }) \\ R(\text { reo })\end{array}\right. \\ N \text { (narración) }\end{array}\right.$ 
En cuanto a la temporalización debemos tener en cuenta que existen dos partes claramente diferenciadas. Por una parte, es necesario analizar el tiempo del discurso que deriva de la lectura del diálogo entre el abogado y su defendido combinando el tiempo presente del discurso con las preguntas en tiempo pasado sobre el día del homicidio. Corresponde al momento más cercano al lector en que se produce el interrogatorio al que somete Jacinto Fuentes al acusado para encontrar argumentos y poder defenderlo. Llegados a este punto la precisión temporal no parece ser necesaria ni relevante por causas que más adelante desvelaremos. Por otra parte, tenemos que hablar del tiempo de la historia que corresponde al momento en que el acusado narra lo acontecido el día de la "desgracia" que es previo al tiempo del discurso y lógicamente está en un pasado más lejano. El lector desconoce cuánto tiempo ha pasado entre el momento del interrogatorio y el momento del asesinato, pero sí sabe que corresponde a ese momento previo y también impreciso en el que sucedieron los hechos: "y un día,..", "porque un día me atufo... y hago una barbaridá", "el día de la cosa..., de la desgracia...".

Efectivamente, el tiempo de la historia se rebela como algo indeterminado, sin fechas concretas, porque los datos relevantes para el lector de esta historia son otros más importantes que conocer el día exacto en que el asesinato tuvo lugar. Creemos pues que esta imprecisión en cuanto a la temporalización del relato ha sido intencionada y está perfectamente justificada porque el maltrato a la mujer es una lacra social que venimos sufriendo desde hace siglos y que, para nuestra desgracia, todavía no ha sido erradicada, de ahí esa atemporalidad.

En cuanto a la espacialización sucede algo parecido a lo que comentábamos en el apartado anterior. Es más importante para la lectura del relato lo que en él se cuenta que saber la ciudad y/o el lugar exacto donde han ocurrido los hechos. No obstante, también se pueden distinguir claramente dos espacios que se corresponden directamente con los dos tiempos anteriormente mencionados. El espacio físico donde el abogado interroga a su defendido se corresponde con la prisión donde está retenido el presunto asesino: "sentado sobre el camastro de su tétrica celda en la Cárcel Modelo". Por otra parte, sabemos que el espacio ficcional donde tuvo lugar el asesinato es la propia casa-hospedaje del matrimonio Rivas porque el acusado lo afirma en varias ocasiones: "Yo tomé posada en ca el Negruzco", "tocante al hospedaje...", "el Negruzco entró en su casa de mal talante, y sin reparar que estaba yo allí...". Por lo tanto, al rasgo de atemporalidad que caracterizaba a este relato debemos sumarle el término universalidad que facilita que esta lectura se pueda efectuar y comprender desde cualquier punto del planeta sin necesidad de precisiones temporales ni localismos.

Estos dos últimos rasgos a los que hemos aludido se presentan como características inherentes a la cuentística tradicional y popular. Tal vez ese sea el motivo por el cual y con frecuencia este tipo de relatos de Emilia Pardo Bazán se incluyan dentro del epígrafe de los cuentos: Cuentos de amor, Cuentos de la tierra, Cuentos de Marineda, Cuentos del terruño, etc. Una vez sembrada la duda en cuanto a la terminología más 
apropiada para definir este tipo de historias y dejando una puerta abierta para que el lector reflexione acerca de si deberían ser llamados cuentos o relatos de ficción es preciso volver al hilo conductor de este apartado para dar cuenta de los personajes de este relato.

El ambicioso abogado defensor Jacinto Fuentes intenta probar por todos los medios que "el Costilla" estaba enamorado de "la Remigia" para configurar la estructura de un típico triángulo amoroso. Si la trama policíaca en la que se enmarca este triángulo fuese completa, el letrado vería cubiertas sus ansias de acumular un "triunfo más sobre los ya obtenidos en su carrera refulgente, que le llevaba hacia un bufete lucrativo". Según este abogado, todo o casi todo, tiene una explicación por la atracción que ejerce sobre el hombre la mujer y viceversa, por lo que, "sólo con la clave amorosa podía el defensor reconstruir el drama lógicamente". Por tanto, este supuesto "crimen pasional" provocado por una furia incontrolable de celos que podría lanzar al estrellato la carrera del abogado y tener una enorme repercusión en los medios, se convierte, pues, en un "vulgar asesinato".

Para evitar lo que creemos sería una enumeración aburrida acerca de los personajes que conforman este relato hemos preferido presentarlos y realizar el estudio de los mismos en dos claves diferentes: una morfológica y otra mitológica. Tomando la terminología empleada por Propp en su Morfología del cuento (1977), el actante Juan Vela, que encarna el papel de héroe, acaba con la figura del agresor, Eugenio Rivas, que ha intentado atrapar en numerosas ocasiones a la princesa que en este cuento no es otra que "la Remigia", víctima de las constantes agresiones de su marido que constituyen la fechoría. En el cuadro que sigue a continuación se aprecian claramente estas relaciones:

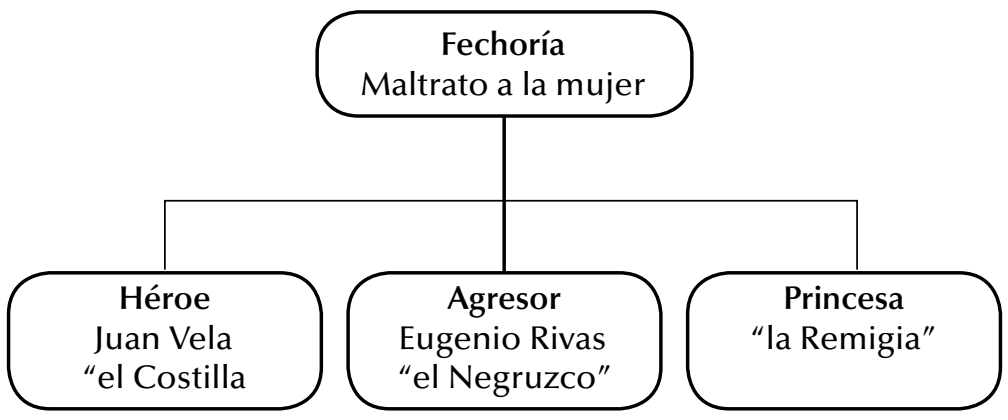

Figura 2. Relación entre los actantes según la terminología de Propp.

Si acudimos ahora a la clave mitológica para establecer relaciones entre los personajes de la historia podemos establecer cierto paralelismo entre éstos y el conocido mito de San Jorge y el dragón ${ }^{20}$. En esta leyenda, que data del siglo IX,

\footnotetext{
${ }^{20}$ El mito de San Jorge y el dragón ha sufrido numerosas interpretaciones a lo largo de los siglos tanto desde el laicismo como del cristianismo y dependiendo de las tradiciones locales varían en mayor o menor medida las interpretaciones que del mismo se han realizado.
} 
San Jorge montado a caballo se erige como el vencedor que salva a la princesa de un terrible dragón que tiene atemorizada a toda una ciudad. Este mito, que probablemente sea el origen de todos los cuentos de hadas, princesas y dragones en Occidente, puede ser aplicado perfectamente para explicar las relaciones entre los personajes del relato que nos ocupa tal y como se detalla en el siguiente cuadro:

\section{Mito de San Jorge y el dragón}

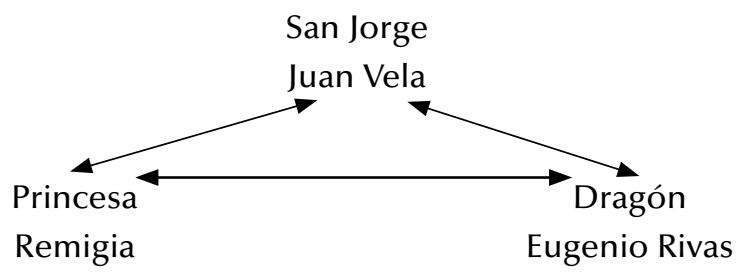

Figura 3. Relación entre los personajes en clave mitológica.

Por mantener la coherencia establecida entre los dos niveles narrativos analizados anteriormente, cabe establecer un tercer esquema en el que se aprecian las relaciones entre los personajes atendiendo precisamente a esos dos niveles de la narración. Por un lado la relación entre el abogado y su defendido en el tiempo del discurso en la Cárcel Modelo y, por otro, el triángulo establecido entre el agresor, la agredida y el defensor en el tiempo de la historia en casa del matrimonio Rivas.

\begin{tabular}{|c|c|}
\hline $\begin{array}{c}\text { Abogado } \\
\text { Jacinto Fuentes }\end{array}$ & NN1 \\
\hline Juan Vela \\
\hline
\end{tabular}

Figura 4. Relaciones entre personajes según los niveles narrativos. 
Todo el recorrido emprendido en el análisis y estudio de los personajes del relato "Sin pasión" queda recogido y puede observarse con claridad mediante esta tabla resumen:

\begin{tabular}{|l|l|l|l|}
\hline Personajes & Juan Vela & Remigia & Eugenio Rivas \\
\hline Apodos & "el Costilla" & "la Remigia" & "el Negruzco" \\
\hline Relación & Huésped & Mujer & Marido \\
\hline Propp & Héroe & Princesa & Agresor \\
\hline Mitología & San Jorge & Princesa & Dragón \\
\hline NN 1 & Homicida & Defendida & Asesinado \\
\hline NN 2 & Defensor & Víctima & Agresor \\
\hline Derecho & Acusado & Testigo & Víctima \\
\hline
\end{tabular}

Figura 5. Tabla resumen con los rasgos característicos de los personajes.

Por último, las relaciones internas entre los personajes del relato se antojan más complicadas de lo que en un principio podría parecer $y$, para mayor abundamiento, es necesario añadir, aunque sea brevemente, que existen otros personajes a los que no hemos mencionado con anterioridad debido a su escaso protagonismo en cuanto a este tipo de conexiones actanciales. El abogado Jacinto Fuentes y el hijo pequeño de los Rivas que representa el papel de testigo observador que no actúa pero está presente durante todo el suceso:

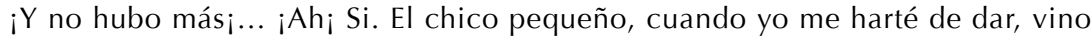
a mirar a su padre, que ya no se movía, y me dijo muy calladito: “¡Bien hecho ${ }^{\prime}$

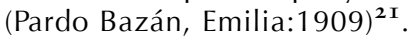

\subsection{Aplicación didáctica}

Teniendo en cuenta que la presentación de una unidad didáctica completa y apropiada para este relato ocuparía un espacio del que no disponemos, nos limitaremos a plantear unas cuantas propuestas siempre de acuerdo con el contexto

\footnotetext{
${ }^{2}$ I Pardo Bazán, Emilia (1909): “Sin pasión” edición digital a partir de Blanco y Negro núm. 930,1909 y cotejada con la edición de Juan Paredes Núñez Cuentos completos, La Coruña, Fundación Pedro Barrié de la Maza, Conde de Fenosa, 1990, t. III, pp. 89-91.
} 
y dentro del marco legislativo en el que nos encontramos. Las aplicaciones didácticas existentes para un relato de estas características podrían ser muchas y muy variadas y dependerán siempre de los objetivos y contenidos acordados previamente. A continuación proponemos varias posibilidades de exploración intentando abarcar las cuatro destrezas de la lengua en sus vertientes oral y escrita.

\subsubsection{Contextualización de la propuesta}

Esta propuesta didáctica se plantea para un grupo mixto de más o menos veinticinco alumnos/as en cualquiera de los niveles de Enseñanza Secundaria y/o Bachillerato en el marco de la materia: "Lengua castellana y literatura". Como decíamos anteriormente, se tienen en cuenta tanto los objetivos como los contenidos establecidos dentro de las órdenes ministeriales correspondientes para el ciclo en cuestión atendiendo especialmente a la expresión oral, comprensión escrita y como tema transversal se trata el maltrato doméstico.

\subsubsection{Competencias, objetivos y contenidos}

El Real Decreto 1631/2006, de 29 de diciembre, por el que se establecen las enseñanzas mínimas correspondientes a la Educación Secundaria Obligatoria y en el marco de la propuesta realizada por la Unión Europea se han identificado ocho competencias básicas:

- Competencia en comunicación lingüística.

- Competencia matemática.

- Competencia en el conocimiento y la interacción con el mundo físico.

- Tratamiento de la información y competencia digital.

- Competencia social y ciudadana.

- Competencia cultural y artística.

- Competencia para aprender a aprender.

- Autonomía e iniciativa personal.

Dentro de este contexto y por razones más que obvias nos centraremos especialmente en la primera de estas competencias: la competencia en comunicación lingüística, que hemos desarrollado a continuación. Pero no por ello debemos olvidar algunas otras competencias básicas que también parecen pertinentes en mayor o menor medida, por ejemplo: la competencia social y ciudadana, o la cultural y artística, así como las dos últimas.

La competencia en comunicación lingüística implica que el lenguaje constituye un instrumento de comunicación oral y escrita, que sirve para representar, interpretar y comprender la realidad, organizar el conocimiento el pensamiento, las emociones y la propia conducta. Adquirir competencia en comunicación lingüística implica además poder expresar pensamientos, emociones, vivencias y opiniones. Con ella se proporciona 
coherencia y cohesión al discurso, se adoptan decisiones y también es posible disfrutar escuchando, leyendo o expresándose de forma oral y escrita, contribuyendo, por lo tanto, al desarrollo de la autoestima y de la confianza en uno mismo.

El lenguaje, tal y como afirma el Real Decreto: "debe ser instrumento para la igualdad, la construcción de relaciones iguales entre hombres y mujeres, la eliminación de estereotipos y expresiones sexistas". Escuchar, exponer, dialogar, leer y escribir son acciones inherentes a la comunicación lingüística y disponer de esta competencia conlleva tener conciencia de las convenciones sociales, de los valores y aspectos culturales y de la versatilidad del lenguaje en función del contexto y la intención comunicativa.

Tanto en el planteamiento de los objetivos, como en la propia selección de los contenidos se busca asegurar el desarrollo de todas las competencias básicas. El objetivo de esta materia es el desarrollo de la competencia comunicativa, es decir, un conjunto de conocimientos sobre la lengua y de procedimientos de uso que son necesarios para interactuar satisfactoriamente en diferentes ámbitos sociales. Concretamente los objetivos generales para esta etapa en la materia: "Lengua castellana y literatura" son: (1) Comprender discursos orales y escritos en los diversos contextos de la actividad social y cultural. (2) Utilizar la lengua para expresarse de forma coherente y adecuada en los diversos contextos de la actividad social y cultural, para tomar conciencia de los propios sentimientos e ideas y para controlar la propia conducta. (3) Conocer la realidad plurilingüe de España y las variedades del castellano y valorar esta diversidad como una riqueza cultural. (4) Utilizar la lengua oral en la actividad social y cultural de forma adecuada a las distintas situaciones y funciones, adoptando una actitud respetuosa y de cooperación. (5) Emplear las diversas clases de escritos mediante los que se produce la comunicación con las instituciones públicas, privadas y de la vida laboral. (6) Utilizar la lengua eficazmente en la actividad escolar para buscar, seleccionar y procesar información y para redactar textos propios del ámbito académico. (7) Utilizar con progresiva autonomía y espíritu crítico los medios de comunicación social y las tecnologías de la información para obtener, interpretar y valorar informaciones de diversos tipos y opiniones diferentes. (8) Hacer de la lectura fuente de placer, de enriquecimiento personal y de conocimiento del mundo y consolidar hábitos lectores. (9) Comprender textos literarios utilizando conocimientos básicos sobre las convenciones de cada género, los temas y motivos de la tradición literaria y los recursos estilísticos. (10) Aproximarse al conocimiento de muestras relevantes del patrimonio literario y valorarlo como un modo de simbolizar la experiencia individual y colectiva en diferentes contextos histórico-culturales. (11) Aplicar con cierta autonomía los conocimientos sobre la lengua y las normas del uso lingüístico para comprender textos orales y escritos y para escribir y hablar con adecuación, coherencia, cohesión y corrección. (12) Analizar los diferentes usos sociales de las lenguas para evitar los estereotipos lingüísticos que suponen juicios de valor y prejuicios clasistas, racistas o sexistas. 
Una de las finalidades de la Educación Secundaria Obligatoria (ESO) es el desarrollo integral y armónico de la persona en los aspectos intelectuales, afectivos y sociales. Para contribuir a ese desarrollo se debe fomentar la educación lingüística, o la capacidad para usar la lengua en las diversas esferas de la actividad social, y la educación literaria, o el conjunto de habilidades y destrezas necesarias para leer de forma competente los textos literarios de nuestra trayectoria cultural.

La selección de los contenidos y los aprendizajes establecidos a través de los objetivos anteriormente citados se recogen en los cuatro bloques de contenidos del currículo: (1) Hablar, escuchar y conversar. (2) Leer y escribir. (3) Educación literaria y (4) Conocimiento de la lengua. La organización de los contenidos del currículo en estos cuatro bloques no tiene como finalidad establecer el orden y la organización de las actividades de aprendizaje en el aula sino que se estructura de este modo para poder profundizar detalladamente en cada uno de estos bloques de contenidos aún sabiendo que todos ellos están perfectamente relacionados y son complementarios entre sí.

$\mathrm{Si}$ entendemos que aprender una lengua es aprender a comunicarse con los otros, a comprender lo que éstos transmiten y a aproximarse a otras realidades, entonces el aprendizaje de la lengua castellana, en este caso concreto, a través de textos literarios como el que presentamos en este artículo contribuye sin ninguna duda al desarrollo global de la competencia comunicativa y, por lo tanto, también contribuye al desarrollo de la competencia social y ciudadana, entendida como un conjunto de habilidades y destrezas para las relaciones, la convivencia, el respeto y el entendimiento entre las personas.

Como se podrá apreciar en el apartado correspondiente y sin profundizar en más detalles, tanto las competencias, los objetivos como los contenidos marcados para esta etapa de la educación han sido contemplados a la hora de proponer las tareas seleccionadas.

\subsubsection{Metodología}

La metodología empleada para realizar esta propuesta didáctica está basada en el aprendizaje de lenguas a través de tareas (Task-Based Language Learning, TBLL) que fue desarrollada por primera vez en la India por el profesor N. Prabhu tras comprobar que sus alumnos podían aprender una lengua fácilmente sin tener que concentrarse exclusivamente en cuestiones lingüísticas. Esta metodología se centra básicamente en la enseñanza y aprendizaje de una lengua partiendo de la posibilidad de pedir al alumnado que realice una serie de tareas significativas haciendo uso de la lengua objeto de aprendizaje. Las tareas requeridas pueden ser muy variadas y la evaluación se basa principalmente en la conclusión de las mismas más que en la valoración precisa acerca del conocimiento y uso de la lengua de destino. De las muchas ventajas que el uso de esta metodología posee destacamos que genera más confianza en el estudiante a la vez que proporciona una mayor fluidez en el uso de la lengua. 
Algunos seguidores de esta metodología que parte eminentemente del enfoque comunicativo de las lenguas son Teresa P. Pica (2005) o Michael Long (1993). De acuerdo con Jane Willis (1996) de la Universidad de Aston (UK), el aprendizaje de lenguas a través de tareas consiste en la realización y consecución de una tarea que se compone de los siguientes elementos: metas y objetivos, entrada de información, actividades, papel del profesor/a, papel del estudiante y configuración de los resultados. Willis recomienda dividir el aprendizaje basado en tareas en tres partes bien diferenciadas:

A. Pre-tarea. El profesor presenta la tarea explorando el centro de interés, dando instrucciones y preparando la actuación del alumnado.

B. Ciclo de elaboración de la tarea. Se compone de tres momentos: la elaboración de la tarea en sí misma, la planificación de la misma por parte de los estudiantes seleccionando la información y, por último, un informe final que se presenta a toda la clase y que se compara con los resultados de otros informes para obtener conclusiones.

C. Enfoque lingüístico. En este momento, el profesor se centra en dos aspectos: uno, el análisis específico de los aspectos lingüísticos surgidos como consecuencia de la elaboración de la tarea incluyendo, si es necesario, otros que sean pertinentes y, dos, la puesta en práctica con actividades y ejercicios de los aspectos lingüísticos que acabamos de citar.

Después de explicar muy sucintamente el funcionamiento de la metodología a emplear para esta propuesta concreta planteamos, por tanto, una serie de tareas que deberán ser llevadas a cabo por el alumnado y posteriormente evaluadas para comprobar el cumplimiento de las metas y objetivos marcados. Huelga decir que para ello hemos tenido en cuenta todos los requerimientos preceptivos tanto a nivel nacional (Reales Decretos) como a nivel europeo (MCERL) y que la aplicación didáctica contempla en todo momento el uso de las cuatro destrezas de la lengua.

\subsubsection{Temporalización, planificación y descripción de las tareas}

Presentamos a continuación, partiendo de este relato de Emilia Pardo Bazán como base de nuestra propuesta, una serie de tareas y actividades para llevar a cabo en el aula de aprendizaje para la materia: "Lengua castellana y literatura". La tarea final consiste en la exposición oral y compartida de las conclusiones obtenidas tras el cumplimiento de las tareas asignadas a cada grupo de estudiantes. La primera de estas tareas consiste en la lectura del relato en voz alta y para toda la clase seguida de una segunda lectura silenciosa e individual en la que se fijarán y asimilarán detalles no percibidos en la primera lectura.

La comprensión lectora se puede constatar por medio de la agrupación el alumnado en asamblea en la que se dan respuestas a las preguntas planteadas por la figura del profesor-mediador. El aprendizaje colaborativo y sus consecuencias positivas forman parte hoy en día de casi todas las propuestas en el aula, por lo que el 
reparto de las tareas en grupos de tres o cuatro alumnos constituye el siguiente paso a seguir en esta aplicación didáctica. Proponemos, por tanto, la realización en grupo de un resumen del relato primero de forma oral y luego por escrito.

En el relato de este crimen atroz falta el componente visceral, no hay crimen pasional, no hay celos, no hay amor prohibido, el propio título lo indica desde el principio como si fuese una especie de guiño al lector: "Sin pasión". Sin embargo, la tarea (también en grupo) de buscar otro título para este relato parece interesante en tanto en cuanto a lo largo de esta investigación siempre pensamos que más que "sin pasión" debería titularse, por ejemplo: "Sin perdón".

Por medio de estas tareas iniciales se ponen en práctica las cuatro destrezas de la lengua atendiendo a los dos primeros bloques de contenidos anteriormente citados. En cuanto a los otros dos bloques que se refieren a la educación literaria y al conocimiento de la lengua en sí misma proponemos las siguientes tareas. Por medio de las nuevas tecnologías resulta fácil, a la vez que motivador, implicar al alumnado en la búsqueda de información relacionada con la vida y obra de la autora de este relato. La búsqueda de datos sobre el tema objeto de estudio no sólo dentro de la obra de la autora sino también en otras fuentes de información: novelas, periódicos, revistas, relatos orales, etc., constituye una actividad que suele motivar y de la cual se puede obtener mucho material lingüístico para el aula de aprendizaje.

El relato de Emilia Pardo Bazán presenta rasgos de estilo relacionados con el lenguaje coloquial propio de la tendencia literaria del realismo-naturalismo en la que la autora se encontraba inmersa. Damos cuenta de algunos de ellos: los apodos para cada uno de los personajes: "el costilla", "el negruzco", "la Remigia", "el Pelele"; las expresiones coloquiales: "en ca el Negruzco", "hago una barbaridá", "le dio una patá", "a andar namorao", "aceituna aliñá", "denegría", "se me ha pasao", "he tenío por costumbre", "no es mu regular", etc. El estudio de los tropos o recursos estilísticos presentes en el texto: epítetos, sinónimos, metonimias, hipérbatos, etc., su detección y el reconocimiento de los mismos en el relato constituye también una interesante fuente de información: "me dijo muy calladito", "el día de la cosa..., de la desgracia...", "que si..., que si..., que si...", etc.

Las posibilidades didácticas que existen en este tipo de textos son muchas y muy diferentes, dependerán de muchos factores tales como: el tiempo disponible dentro de la programación de centro y de aula, el número y el nivel de los estudiantes o la motivación obtenida al realizar las tareas. Hemos querido presentar aquí sólo una pequeña muestra de algunas tareas que podrían ser desarrolladas ampliamente en un contexto didáctico más apropiado y sin las limitaciones espaciales a las que nos vemos subordinados.

\subsubsection{Material, fuentes de información y evaluación}

En cuanto a los materiales a utilizar para el desarrollo de las tareas planteadas se puede afirmar que son muchos y muy variados aunque partimos del relato literario como texto base inicial y de ahí podríamos elaborar muchos otros materiales. Por 
ejemplo, la posibilidad de dramatizar el relato de E. Pardo Bazán para su posterior representación por parte de los alumnos constituye una fuente enorme de producción de material lingüístico.

En cuanto a la evaluación de las tareas podríamos decir, en términos muy generales, que la consecución de las mismas y puesta en común en el aula para su posterior verificación constituye en sí misma un ejercicio de evaluación y valoración de la adquisición de los contenidos.

De entre los criterios de evaluación propuestos para la etapa de enseñanza secundaria describimos a continuación unos cuantos extraídos del tercer curso que hemos tomado como ejemplo de referencia para demostrar que con un texto literario como el que hemos elegido para este análisis se pueden y deben cumplir sobradamente. Algunos de estos criterios son: ser capaz de extraer ideas generales e informaciones específicas, seguir el desarrollo de presentaciones breves y plasmarlas en forma de esquema y resumen. Poder identificar el propósito en los textos escritos más usados. Saber narrar, exponer, explicar, resumir y comentar usando el registro adecuado, organizando las ideas con una buena presentación de los textos escritos tanto en soporte papel como digital con respeto a las normas ortográficas y tipográficas.

También se incluye entre estos criterios la capacidad para realizar explicaciones orales sencillas y saber exponer una opinión sobre la lectura personal de una obra completa adecuada a la edad y relacionada con los periodos literarios estudiados y sobre la implicación entre su contenido y las propias vivencias. Utilizar los conocimientos literarios en la comprensión y la valoración de textos breves o fragmentos, atendiendo a la presencia de ciertos temas recurrentes. Mostrar conocimiento de las relaciones entre las obras leídas y comentadas, el contexto en que aparecen y los autores más relevantes realizando un trabajo personal de información y de síntesis o de imitación y recreación, en soporte papel o digital. Y, por último, saber aplicar los conocimientos sobre la lengua y las normas del uso lingüístico para resolver problemas de comprensión de textos orales y escritos o conocer la terminología lingüística necesaria para la reflexión sobre el uso son otros de los criterios de evaluación a tener en cuenta para esta etapa educativa.

\subsubsection{Atención a la diversidad, estudiantes con necesidades especiales y temas transversales}

Por lo que respecta a este apartado sobre la atención a la diversidad y a estudiantes con necesidades especiales no parece procedente extenderse en este particular sin facilitar datos más concretos del número y características de los estudiantes a quienes iría dirigida esta propuesta. Por el contrario, sí es pertinente y muy oportuno aludir a los temas transversales a los que se refiere el currículo para Enseñanza Secundaria.

Si entendemos que la enseñanza y aprendizaje de lenguas a través de textos literarios contiene o debe contener una finalidad educativa, la historia de este relato constituye en sí misma un tema transversal muy interesante y apropiado para las 
edades a las que va dirigida esta aplicación didáctica. En este texto de ficción se relata de forma clara y concisa un crimen atroz en el que apreciamos una total ausencia del componente visceral, no hay crimen pasional, no hay celos, no hay amores prohibidos...; lo que sí hay es un ejemplo de un acto memorable de censura y castigo por malos tratos a una mujer. Este tipo de sucesos se escapa de las barreras del tiempo y del espacio de la ficción en el que se enmarca constituyendo una de las lacras sociales con las que nos vemos obligados a convivir. Emilia Pardo Bazán contribuyó con éste y otros escritos a denunciar y condenar estas manifestaciones de violencia de género.

\section{CONCLUSIÓN}

Para concluir este artículo recapitulamos nuestras pretensiones iniciales que comienzan por el lanzamiento de una hipótesis constatando el conocimiento de Emilia Pardo Bazán acerca de la existencia de un caso real y cercano de violencia de género en su propia familia más directa que creemos marcó no sólo su vida sino también su producción literaria. Asimismo constatamos a través de sus escritos el compromiso férreo que tenía con la sociedad de su tiempo y con los problemas de desigualdad y maltrato a las mujeres.

En éste y los demás relatos a los que hemos aludido en esta investigación hemos encontrado grandes dosis de denuncia social acerca del maltrato doméstico que, lejos de ser un fantasma del pasado se repite con demasiada frecuencia incluso en nuestros días. En este texto, la primera víctima logra salvarse porque una tercera persona ha salido en su defensa tomándose la justicia por su mano, pero, a su vez, ese defensor de la injusticia se convertirá ahora en otra víctima que no quedará libre de recibir su castigo porque a la vista de que el caso se presentaba "borroso y deslucido", el abogado Fuentes decide ya en su interior "no apretar. Pues lo que es este, de presidio no se escapa".

Tímidamente hemos querido animar al lector y también a los investigadores en este campo a profundizar en el uso correcto de la terminología narrativa queriendo hacer especial hincapié en la diferencia existente entre los términos "relato breve" y "cuento" considerando este último mal utilizado por los editores de la producción literaria de la Condesa.

En la elaboración de este artículo hemos pretendido también realizar un riguroso análisis semiótico-textual bien argumentado que da cuenta de los elementos principales que lo configuran. Como si de un cirujano se tratase, hemos diseccionado el texto de ficción analizando y explicando cada una de las partes que lo componen para luego volver a recomponerlo y darle un sentido global y exclusivo.

Con la firme consideración de que un análisis científico de nada serviría si luego no es posible darle una utilidad práctica hemos recuperado un texto literario del siglo pasado acercándolo a la actualidad y a la realidad de un aula de Secundaria para demostrar las posibilidades didácticas que este tipo de relatos puede llegar a tener. La metodología empleada, que creemos resulta muy útil, ha sido explicada 
sucintamente para poder realizar la propuesta didáctica y, finalmente, hemos defendido el uso de este tipo de textos no sólo como material literario, sino también como material lingüístico muy valioso para la enseñanza y aprendizaje de lenguas en general y para la DLL en particular.

\section{BIBLIOGRAFÍA}

Blanqué, A. (2002): "Emilia Pardo Bazán: una voz gallega", La Jornada semanal. (2 de junio de 2002), p. 378. Disponible en: http://www.jornada.unam. mx/2002/06/02/sem-andrea.html (consulta: 2-06-2008).

Bravo-Villasante, C. (1962): Vida y obra de Emilia Pardo Bazán, Revista de Occidente, Madrid.

Carballal Miñán, P. (2012): "Rabeno" de Emilia Pardo Bazán: mito y reflexión didáctica sobre la violencia sexual" en La Tribuna. Cadernos de estudos da CasaMuseo Emilia Pardo Bazán, no 8, pp. 97-106.

Couto Cantero, P. (2011): "Teaching and Learning EFL through PBL". Sociology Study, vol. 1, (4), 272-281.

Ellis, R. (2003): Task-based Language Learning and Teaching, Oxford, Oxford University Press.

González Herrán, J. M. et al. (2006): Emilia Pardo Bazán: Los Cuentos. Actas del II Simposio, La Coruña, Real Academia Galega-Fundación Caixa Galicia.

Herrero Figueroa, A. (2004): Estudos sobre Emilia Pardo Bazán e recompilación de dispersos, Lugo, Diputación Provincial. [Disponible en: <cervantesvirtual.com>].

(2007): "La condesa de Pardo Bazán y la lectura infantil y/o juvenil" en Anuario de Investigación en Literatura Infantil y Juvenil, nº 5, 109-138.

(2012): “Emilia Pardo Bazán. "Feminista: desigualdad intergenérica y maltrato doméstico", en La Tribuna. Cadernos de estudos da Casa-Museo Emilia Pardo Bazán, nº 8, pp. 57-70.

Long, M. H., \& Crookes, G. (1993): "Units of analysis in syllabus design - The case for task", in G. Crookes \& S. M. Gass (Eds.): Tasks in a pedagogical context: Integrating theory and practice, Clevedon, UK, Multilingual Matters. pp. 9-54.

Pardo Bazán, E. (agosto 1890): "La mujer española. El pueblo", en La España Moderna, núm 20, pág. 154.

Pardo Bazán, E. (1990): Cuentos completos, Juan Paredes Núñez (ed.), Fundación Pedro Barrié de la Maza, La Coruña, 4 vols.

Pardo Bazán, E. (1999): Obras Completas, Fundación José Antonio de Castro, Madrid.

Pardo Bazán, E. (1972): La vida contemporánea. Editorial Magisterio Español, Madrid. 
Pardo Bazán, E. (2005): La vida contemporánea, Carlos Dorado (ed.), Madrid, Hemeroteca Municipal de Madrid.

Patiño Eirín, C. (1998): Poética de la novela en la obra crítica de Emilia Pardo Bazán, Santiago de Compostela, Universidad de Santiago de Compostela.

Peñas Ruiz, A. (2008): "Emilia Pardo Bazán: Cartografías en torno a la mujer" en La Tribuna. Cadernos de estudos da Casa-Museo Emilia Pardo Bazán, nº 6, 145-172.

Pica, T. (2005): "Classroom learning, teaching, and research: A task-based perspective", The Modern Language Journal, 89(3): 339-352.

Propp, Vladimir (1977): Morfología del cuento, Madrid, Editorial Fundamentos.

Ruiz-Ocaña, E. (2004): "Emilia Pardo Bazán y los asesinatos de mujeres", Didáctica (Lengua y Literatura), 16, 177-188.

Willis, J. (1996): A Framework for Tasked-Based Learning, London, Longman.

Relatos citados en este artículo por orden cronológico:

"El indulto" (1883).

"En tranvía" (1890).

"La novia fiel" (1894) recogido en Cuentos de amor.

"De Navidad" (1896).

"El encaje roto" (1897) recogido en Cuentos de Amor.

"Sin pasión" (1909).

"Feminista" (1909).

"Rabeno" (1910).

"Las medias rojas" (1914).

"La advertencia" (s.a.) recogido en Cuentos de la tierra. 